А. А. Райченок

Белорусский государственный технологический университет

\title{
ИСТОРИОГРАФИЯ БЕЛОРУССКОЙ ГОСУДАРСТВЕННОСТИ 20-Х ГГ. ХХ В. КАК ФОРМА ОТРАЖЕНИЯ ИСТОРИЧЕСКОЙ ПАМЯТИ
}

В статье дается обзор основных направлений становления и развития исторической памяти в Беларуси через призму первых исследований феномена белоруской государственности в 20-х гг. ХХ в. Прослеживается развитие методологии историографических исследований и формирование исторической политики в БССР. Рассматривается проблема введения корректного научного инструментария в исследовании исторической памяти современной исторической наукой. Исследуется влияние идеологических приоритетов, представителей тех или иных политических течений Беларуси 1920-х гг. на становление белорусской историографии модерной белорусской государственности. В статье рассматриваются вопросы влияния политического и социального заказов на тематику профессиональных исторических исследований и их дальнейшего воздействия на процесс формирования коллективной памяти, а также специфика их научного представления. Автором оцениваются перспективы исследования феномена исторической памяти в современной историографии Беларуси.

Ключевые слова: историография, историческая память, государственность, БНР, БССР, нация, национал-демократизм, большевизм, историческая наука.

Для цитирования: Райченок А. А. Историография белорусской государственности 20-х гг. $\mathrm{XX}$ в. как форма отражения исторической памяти // Труды БГТУ. Сер. 6, История, философия. 2021. № 1 (245). С. 12-17.

\section{A. A. Raichonak \\ Belarusian State Technological University \\ HISTORIOGRAPHY OF THE BELARUSIAN STATEHOOD IN THE 20s XX CENTURY AS A FORM OF REFLECTION OF HISTORICAL MEMORY}

The article provides an overview of the main directions of the formation and development of historical memory in Belarus through the prism of the first studies of the phenomenon of Belarusian statehood in the 1920s. XX century. The development of the methodology of historiographic research and the formation of historical policy in the BSSR are traced. The problem of introducing correct scientific tools in the study of historical memory by modern historical science is considered. The influence of ideological priorities, representatives of certain political trends in Belarus in the 1920s is investigated. on the formation of the Belarusian historiography of the modern Belarusian statehood. The article examines the influence of political and social orders on the topics of professional historical research and their further impact on the process of forming collective memory, as well as the specifics of their scientific presentation. The author assesses the prospects for studying the phenomenon of historical memory in the modern historiography of Belarus.

Key words: historiography, historical memory, statehood, BNR, BSSR, nation, national democracy, Bolshevism, historical science.

For citation: Raichenok A. A. Historiography of the Belarusian statehood in the 20s XX century as a form of reflection of historical memory. Proceedings of BSTU, issue 6, History, Philosophy, 2021, no. 1 (245), pp. 12-17 (In Russian).

Введение. Во вступлении к статье хотелось бы заметить, что история сама по себе может быть определена как наука о памяти, а учреждения, отвечающие за ее разработку, изучение, сохранение и увековечивание, можно назвать учреждениями памяти. К ним могут быть отнесены академические институты и факультеты университетов, архивы и библиотеки, музеи и мемориальные комплексы, книги и все виды документальных источников включая устную историю.

Политическое использование истории является постоянным явлением, элиты рационализируют и пересматривают эту память в свете своей идеологии и интересов. Но есть разница между официальной памятью, которая разрабатывается и транслируется государством или общественными органами для прославления, 
мифологизации или сокрытия событий с целью поддержания национальной идентичности, и общественной памятью, которая характеризуется как воля или желание со стороны какой-либо социальной группы или индивидуумов дать свое видение исторических процессов и своей роли в них. Склонность власти отбирать и организовывать представления о прошлом так, чтобы они могли восприниматься людьми как свои собственные, прослеживается на протяжении всей истории человечества. Между тем альтернативные версии подвергаются жесткой критике или вовсе предаются забвению. В этой связи особый интерес вызывает дискуссия, развернувшаяся в 1920-х гг., по проблеме становления и сущности белорусской государственности. Одним из важнейших источников в освещении данной проблемы является литература, созданная представителями белорусского национально-демократического движения, а также их оппонентами - большевиками. Ценность этих работ заключается в том, что авторы не только были свидетелями тех исторических событий, но и оказали на них непосредственное влияние. С другой стороны, это связано с их главным недостатком - субъективизмом в интерпретации исторических событий.

Основная часть. Одной из первых работ, посвященных анализу данных процессов, была работа Председателя Народного совета министров Белорусской Народной Республики в 1918-1919 г., Луцкевича А. И. - «Политические лозунги белорусского движения» [1], содержащаяся в сборнике «Наша Ніва». В работе представлена эволюция взглядов белорусского национального движения с 1916 по 1920 г., описан первый этап становления белорусской государственности и направления его возможного развития. Его же «Через двадцать пять лет» [2] по сути, первая попытка создать обобщенный труд по истории белорусского движения первой четверти XX в., в котором он утверждает, что БССР лишь частично реализовала государственный идеал, а также объясняет роль декларации независимости БНР в процессе государственного строительства. В целом А. Луцкевич оставил после себя довольно богатое литературное наследие, которое является важным источником в исследовании не только проблемы становления белорусской государственности, но и белорусского национального движения в целом.

Интересны публикации Е. Я. Варонки, который с февраля по июль 1918 г. был председателем Народного секретариата Беларуси, а с декабря 1918 по апрель 1920 г. - министром по делам Беларуси и членом Кабинета Министров Литвы. В книгах «Белорусский вопрос к моменту Версальской мирной конференции: ист.- полит. очерк» [3] и «Белорусское движение с 1917 по 1920 год: краткий обзор» [4] он поддерживает концепцию «двух врагов» - Польши и России, которые в равной степени угрожают государственной независимости Беларуси.

Проблема путей становления белорусской государственности нашла отражение и в творчестве активного участника национального движения, премьер-министра правительства БНР в 1923-1925 гг. Цвикевича А. И.

Брошюра «Краткий очерк происхождения Белорусской Народной Республики» [5] дает краткий анализ предпосылок провозглашения БНР, а также характеризует развитие белорусского движения. В политическом очерке «Беларусь» [6] А. Цвикевич развивает предыдущие положения и особый уклон делает на анализе отношений между Беларусью, Россией и Польшей. Но самая основательная среди рассматриваемых его работ - это книга «Возрождение Беларуси и Польши» [7], в которой анализируется период с 1772 по 1920 г. В результате этого анализа автор приходит к выводу, что Беларусь - это совершенно уникальная страна, и поэтому, как и другие народы, белорусы имеют право на создание собственной национальной государственности, которая должна освободить их от зависимости и положить конец аннексии соседями. Книга А. Цвикевича «Западный русизм» также напрямую связана с данной темой [8]. В ней автор исследует влияние этой идеологии на развитие национального движения и формирование белорусской государственности.

В 1918 г. патриарх белорусской исторической науки Довнар-Запольский М. В. написал небольшую брошюру «Основы государственности Беларуси» [9], переведенную на разные языки и разосланную представительствам БНР за рубежом. Эта брошюра должна была служить идеологическим обоснованием права белорусов на формирование собственной государственности.

Особый интерес вызывает наследие непосредственного участника событий, председателя Белорусского областного комитета при Всероссийском съезде крестьянских депутатов (БОК) Канчара Я. В 1918 г. вышел его очерк «Из истории социальных, национальных и революционных движений белорусов» [10], в котором дано подробное описание Первого Всебелорусского съезда с точки зрения его непосредственного организатора и участника. На характеристику событий автором, безусловно, повлияла его собственная политическая позиция (Я. Канчар был сторонником автономии Беларуси в составе Российской Федерации), что привело к негативной оценке действий как сторонников декларации 
независимости, так и минских большевиков, разогнавших съезд.

В книге «Белорусский вопрос» [11] автор пытается всесторонне осветить белорусское движение, поэтому книга содержит статистику, исторический обзор и анализ культурных особенностей белорусского народа. Но основной акцент автор делает на рассмотрении белорусского национального движения, выделяя его главные требования и обосновывая право белорусского народа на самоопределение.

Следующим представителем белорусской историографии, чья позиция была близка к большевизму, стал Турук Ф.Ф. - председатель Белорусской народной громады (БНГ), образованной в Москве белорусами-беженцами. БНГ имела довольно умеренную программу: национально-территориальная автономия Беларуси и введение самоуправления. В его работе «Белорусское движение» [12] дается краткий обзор белорусского национального движения, отдельные главы посвящены становлению БНР и БССР, дана их общая характеристика и направления развития. Для книги характерна дифференциация белорусских партий по их близости к РКП(б).

Литература, созданная представителями белорусского национального движения, имеет большое значение для изучения становления белорусской историографии. Написанная непосредственными участниками событий, несмотря на определенную субъективность в изложении тех или иных эпизодов, она содержит не только ценную информацию, но и дает возможность понять разнообразие и сложность подходов различных политических кругов к белорусской государственности.

По-разному оцениваются события в изданиях большевистского направления, вышедших в БССР в 20-е гг. прошлого века. Для них характерно неприятие иных взглядов на процесс создания белорусской государственности. Если в начале 1920-х гг. определенный плюрализм еще считался приемлемым, то в конечном итоге всех представителей белорусского национального движения, не стоящих на позиции коммунистической партии, стали обвинять в контрреволюции. Но, несмотря на вышесказанное, именно в эти годы были заложены основы советской историографии государственности Беларуси, ставшие господствующими на последующие семь десятилетий.

Пальма первенства здесь принадлежит первому главе правительства БССР Жилуновичу Д. Ф. В 1923-1926 гг. он опубликовал ряд статей в журнале «Полымя», посвященных данной проблематике. Главная ценность этих публикаций в том, что они затрагивают практически все аспекты государственного строительства в Бела- руси и написаны непосредственным участником событий, показывают развитие белорусского национального движения с точки зрения его радикально левого крыла [13]. Также Жилуновичу принадлежит статья «Февраль - октябрь в белорусском национальном движении» [14], опубликованная в сборнике «Беларусь». Она посвящена процессу размежевания белорусского национального движения на различные, преимущественно левые, направления и кристаллизации их политических требований.

Сборник вышел к пятилетию провозглашения БССР, содержит ряд статей по различным аспектам государственного строительства. Там же размещена статья В. Г. Кнорина, секретаря Центрального бюро КП(б) Белоруссии, «Коммунистическая партия Беларуси» [15], в которой автор пытается проанализировать как положительные, так и отрицательные стороны деятельности коммунистической партии в Беларуси, ссылаясь на фактическое игнорирование последней белорусского национального вопроса в 1917-1918 гг. Северо-Западным комитетом РКП(б).

В. Г. Кнорин посвятил много публикаций другим вопросам партийного и государственного строительства в БССР [16]. Описывая его творчество, следует отметить, что он рассматривает вопрос построения белорусской государственности исключительно через призму классового подхода и коммунистической идеологии. Несмотря на значительную эволюцию его взглядов, от отрицания существования белорусской нации до признания права белорусов на самоопределение, он понимал это самоопределение исключительно на классовой основе и идеологии большевизма. Кнорин считал создание БССР апогеем развития белорусского национального движения и единственно возможной формой реализации идеи белорусской государственности. Он крайне негативно относился к другим взглядам на эти процессы и зачислял в контрреволюционеры всех, кто не разделял взглядов большевиков.

Примерно такая же позиция была характерна и для А. Червякова, Председателя ЦИК БССР. В книге «За Советскую Беларусь» [17] среди прочего он рассматривает проблему создания белорусской государственности. Как и в творчестве В. Кнорина, здесь отчетливо прослеживается приоритет классовых вопросов над национальными. Не только стремление к независимости, но и к автономии Беларуси кажется реакционным, а Всебелорусский съезд, по мнению автора, состоял исключительно из врагов Советской власти. Но здесь следует отметить, что, несмотря на некоторое сходство в подходах, А. Червяков и В. Кнорин были представителями разных течений в ВКП(б). 
Последней в этой серии работ можно назвать статью Г. Паречина «Идея белорусской государственности до образования Советской Беларуси» [18]. По сути, это первая обобщающая работа представителя советского направления по истории развития и эволюции идеи белорусской государственности. В ней исследуется период с XIX в. по 1919 г., прослеживается последовательное развитие идеи белорусской государственности от требования автономии до требования независимости, для нее характерны те же недостатки, обусловленные идеологическими требованиями. Например, БНР характеризуется как «буржуазно-помещичье» государство, а БССР - как «свободное независимое советское государство», что явно является преувеличением.

Характеризуя период 1920-х гг. в целом, можно отметить, что для него присуща постепенная эволюция от мирного сосуществования разных идей по проблеме создания белорусской государственности к доминированию большевистского взгляда на проблему, что в итоге привело к закреплению в историографии белорусской государственности догматического подхода, который просуществовал с небольшими модификациями до конца 80-х гг. XX в.

Вывод. Подводя итоги, следует отметить, что в данный период были заложены две традиции, которые станут доминирующими в белорусской историографии на протяжении всего
XX в. Первая из них, которую условно можно назвать национал-демократической, выводила белорусскую модерную государственность в первую очередь из белорусского национального движения, развернувшегося в конце XIX - нач. $\mathrm{XX}$ в., итогом которого стало провозглашение БНР. Отношение к БССР было противоречивым: с одной стороны, не отрицались некоторые достижения в области развития национальной культуры, с другой - указывалось на ее полную политическую несамостоятельность.

Следует отметить, что данная точка зрения существовала исключительно за пределами БССР и была введена в научный оборот только после «перестройки», начавшейся в СССР во второй половине 1980-х гг.

В Восточной Беларуси, на территории которой в рассматриваемый период была создана БССР, утвердилась иная точка зрения, выводившая белорусскую государственность из классовой борьбы между эксплуататорами и эксплуатируемыми. Вершиной ее стала Октябрьская революция и как следствие - провозглашение БССР как государства рабочих и крестьян, строящегося на основе диктатуры пролетариата.

Статья выполнена при поддержке БРФФИ в рамках совместного белорусско-российского проекта «Историческая культура белорусов и россиян: формирование представлений о национальном и общем прошлом».

\section{Список литературы}

1. Новіна Ант. (Луцкевіч А.). Палітычныя лозунгі беларускага руху // Зборнік «Наша Ніва». Вільня: Бел. выд. т-ва, 1920. С. 2-14.

2. Луцкевіч А. За дваццаць пяць гадоў (1903-1928): Успаміны аб працы першых беларускіх арганізацыяў: Беларуская рэвалюцыйная грамада, Беларуская сацыялістычная грамада. Вільня: Бел. Выд. Т-ва, 1928. 52 с.

3. Воронко И. Я. Белорусский вопрос к моменту Версальской мирной конференции: ист.-полит. очерк. Ковна, 1919. 59 с.

4. Варонка Я. Беларускі рух ад 1917 да 1920 году: кароткі агляд. Коўна, 1920. 29 с.

5. Цвикевич А. Краткий очерк возникновения Белорусской Народной Республики. Киев, 1918. $16 \mathrm{c}$.

6. Цвикевич А. Беларусь: Политический очерк. Берлин, 1919. 32 с.

7. Цвікевіч А. Адрадженне Беларусі і Польшча. Мінск; Вільня; Берлін: Выд. т-ва «Вызваленне», 1921. 192 с.

8. Цвікевіч А. «Заподно-русизм»: нарысы з гісторыі грамадзянскай мысьлі на Беларусі ў XIX і пач. ХХ ст. 2-е выд. Мінск, 1993. 352 с.

9. Доўнар-Запольскі М. В. Асновы дзяржаўнасці Беларусі. Мінск: ВПП Дзяржэканомплана Рэспублікі Беларусь, 1994. 23 с.

10. Канчер Е. С. Из истории общественных, национальных и революционных движений белорусов. Часть II. История возникновения и деятельность организаций. Выпуск первый // Неман. 1993. № 1. C. 136-167.

11. Канчер Е. С. Белорусский вопрос. Петроград, 1919. 132 с.

12. Турук Ф. Белорусское движение: Очерк истории национального и революционного движения белорусов. М.: Госиздат, 1921. 144 с.

13. Жылуновіч 3. Два бакі беларускага руху // Полымя. 1923. № 3-4. С. 69-74; Уступамі да Акцябра // Полымя. 1923. № 5-6. С. 141-149, № 7-8. С. 86-91; Ад Кастрычніка 1917 да лютага 1918 // 
Полымя. 1924. № 1. С. 15-167; Арганізацыя сіл : Да гісторыі Савецкай Беларусі // Полымя. 1924. № 2. С. 163-179; Гістарычны момант // Полымя. 1924. № 4. С. 144-158; 3’езд беларускіх нацыянальных арганізацый 25 сакавіка 1917 года // Полымя. 1925. № 6. С. 202-206; Беларуская інтэлігенцыя ў гістарычным аспекце // Полымя. 1926. № 6. С. 74-98.

14. Жылуновіч 3. Люты - Кастрычнік у беларускім нацыянальным руху. Беларусь: Нарысы гісторыі, эканомікі, культурнага і вызваленчага руху. 1924. С. 182-194.

15. Кнорын В. Г. Камуністычная партыя на Беларусі // Беларусь. 1925. С. 215-222.

16. Кнорин В. Революция и контрреволюция в Белоруссии. Смоленск, 1920. 65 с.; 1917 год в Беларуси и на Западном фронте. Минск, 1925. 76 с.; За культурную революцию. Минск, 1928. $106 \mathrm{c}$.

17. Чарвякоў А. За Савецкую Беларусь. Мінск, 1927. 135 с.

18. Парэчын. Г. Ідэя беларускай дзяржаўнасці перад утварэннем Савецкай Беларусі // Запіскі аддзелу гуманітарных навук. Працы кафедры сучаснага права. 1929. С. 1-35.

\section{References}

1. Novina Ant. (Lutskevich A.). Political slogans of the Belarusian movement. Zbornik "Nasha Niva" [Collection "Nasha Niva"]. Vil'nya, Bel. vyd. t-va Publ., 1920. pp. 2-14 (In Belarusian).

2. Lutskevich A. Za dvatstsats' pyats' gadou (1903-1928): Uspaminy ab pratsy pershykh belaruskikh arganizatsyyau: Belaruskaya revalyutsyynaya gramada, Belaruskaya satsyyalistychnaya gramada [For twenty-five years (1903-1928): Memoirs of the work of the first Belarusian organizations: the Belarusian Revolutionary Society, the Belarusian Socialist Society]. Vil'nya, Bel. vyd. t-va Publ., 1928. $52 \mathrm{p}$.

3. Voronko I. Ya. Belorusskiy vopros $k$ momentu Versal'skoy mirnoy konferentsii [The Belarusian question at the time of the Versailles Peace Conference]. Kovna, 1919. 59 p.

4. Varonka Ya. Belaruski rukh ad 1917 da 1920 godu: karotki aglyad [The Belarusian movement from 1917 to 1920: A brief overview]. Kouna, 1920. 29 p.

5. Tsvikevich A. Kratkiy ocherk vozniknoveniya Belorusskoy Narodnoy Respubliki [A brief outline of the emergence of the Belarusian People's Republic]. Kiev, 1918. 16p.

6. Tsvikevich A. Belarus': Politicheskiy ocherk [Belarus: Political Sketch]. Berlin, 1919. 32 p.

7. Tsvikevich A. Adradzhenne Belarusi i Pol'shcha [Revival of Belarus and Poland]. Minsk; Vil'nya; Berlin, Vyd. t-va. "Vyzvalenne" Publ., 1921. 192 p.

8. Cvikevich A. "Zapodno-rusizm": narysy z gistoryi gramadzyanskay mys'li na Belarusi u XIX $i$ pach. XX st. ["Western Russism": essays on the history of civic thought in Belarus in the XIX and early XX century]. Minsk, 1993. $352 \mathrm{p}$.

9. Dounar-Zapol'ski M. V. Asnovy Dzyarzhaunastsi Belarusi [Fundamentals of the Statehood of Belarus]. Minsk, VPP Dzyarzhekanomplana Respubliki Belarus' Publ., 1994. 23 p.

10. Kancher E. S. From the history of social, national and revolutionary movements of Belarusians. Neman [Neman], 1993, no. 1, pp. 136-167 (In Russian)

11. Kancher E. S. Belorusskiy vopros [Belarusian question]. Petrograd, 1919. 132 p.

12. Turuk F. Belorusskoye dvizheniye: Ocherk istorii natsional'nogo i revolyutsionnogo dvizheniya belorusov [Belarusian Movement: Essay on the History of the National and Revolutionary Movement of Belarusians]. Moscow, Gosizdat, Publ., 1921. 144 p.

13. Zhylunovich Z. Two sides of the Belarusian movement. Polymya [Flame],1923, no. 3-4, pp. 6974; Introductions to October. Polymya [Flame], 1923, no. 5-6, pp. 141-149, no. 7-8, pp. 86-91; From October 1917 to February 1918. Polymya [Flame], 1924, no. 1, pp. 153-167; Organization of forces. To the history of Soviet Belarus. Polymya [Flame], 1924, no. 2, pp. 163-179; A historical moment. Polymya [Flame], 1924, no. 4, pp. 144-158; Congress of Belarusian national organizations on March 25, 1917. Polymya [Flame], 1925, no. 6, pp. 202-206; Belarusian intelligentsia in the historical aspec. Polymya [Flame], 1926, no. 6. pp. 74-98 (In Belarusian).

14. Zhylunovich Z. February - October in the Belarusian national movement. Belarus': Narysy gistoryi, ekanomiki, kul'turnaga i vyzvalenchaga rukhu [Belarus: Essays on History, Economy, Cultural and Liberation Movement]. Minsk, 1924, pp. 182-194.

15. Knoryn V. G. The Communist Party in Belarus. Belarus' [Belarus], 1925, pp. 215-222 (In Belarusian).

16. Knorin V. Revolyutsya i kontrrevolyutsiya v Belorussii [Revolution and counter-revolution in Belarus]. Smolensk, 1920. 65 p.; 1917 god v Belarusi $i$ na Zapadnom fronte [1917 in Belarus and on the Western Front]. Minsk, 1925. 76 p.; Za kul'turnuyu revolyutsiyu [For the cultural revolution]. Minsk, 1928. $106 \mathrm{p}$. 
17. Charvyakoy̆ A. Za Saveckuyu Belarus' [For Soviet Belarus]. Minsk, 1927. 135 p.

18. Parechyn G. The idea of Belarusian statehood before the formation of Soviet Belarus. Zapiski addzelu gumanitarnykh navuk. Pratsy kafedry suchasnaga prava [Notes of the Department of Humanities. Proceedings of the Department of Modern Law]. Minsk, 1929, pp. 1-35 (In Belarusian).

\section{Информация об авторе}

Райченок Александр Александрович - кандидат исторических наук, доцент кафедры истории Беларуси и политологии. Белорусский государственный технологический университет (220006, г. Минск, ул. Свердлова, 13a, Республика Беларусь). E-mail: raichonak@belstu.by

\section{Information about the author}

Raichonak Aliaksandr Aliaksandravich - PhD (History), Assistant Professor, the Department of History of Belarus and Political Science. Belarusian State Technological University (13a, Sverdlova str., 220006, Minsk, Republic of Belarus). E-mail: raichonak@belstu.by 